\title{
Countermeasure Research on the Development of Cross-border E-commerce between Henan province and BRICS countries
}

\author{
Jianhua Liu ${ }^{1}$, Mingzhao Wang ${ }^{1, *}$, and Ruijundi Ma ${ }^{1}$ \\ ${ }^{1}$ School of Management Engineering, Zhengzhou University, Zhengzhou 450001, China \\ mingzhao636@outlook.com
}

Keywords: Cross-border e-commerce, BRICS, logistics network, supply chain, informatization

\begin{abstract}
In recent years, as Zhengzhou has become the first batch of cross-border e-commerce pilot cities, crossborder e-commerce of Henan has witnessed great development. in face of the huge market space of BRICS countries and convenient cross-border online shopping, Henan province should make full use of the advantages of manufacturing and the position of transportation hub to develop cross-border e-commerce. At the same time, Henan should promote industrial upgrading and logistics network construction, so that cross-border e-commerce can become the next growth point of economic development in Henan province.
\end{abstract}

\section{INTRODUCTION}

In recent years, our government and society attach great importance to the development of cross-border ecommerce, and also regards cross-border e-commerce as the driving force of China's economic development, the direction of industrial transformation and the new window of opening to the outside world. BRICS countries that has similar economic development situation in China are the key markets of cross-border ecommerce to us. As a major manufacturing province in China, Henan has a group of influential brands, the construction of the Zhengzhou airport and Yubei ecommerce park also provide the conditions for the further development of cross-border e-commerce. Therefore, how to make good use of the advantages of Henan province to develop cross-border e-commerce with BRICS countries has become an urgent problem to be solved.

In the field of cross-border e-commerce, many domestic scholars have studied it. Among them, Hou Xiaokun analyzes the trade data of e-commerce, and draws the advantages and disadvantages of developing cross-border e-commerce in China and BRICS countries (Xiaokun Hou,2015). Zhou Xiaorui analyzed the problems existing in the logistics distribution of Zhengzhou Airport (Xiaorui Zhou,2016). Zhang Xuemei use the collaborative innovation theory to put forward the development advices of cross-border e-commerce in Ningbo recommendations (Xuemei Zhang,2016). Most scholars have studied the development path of crossborder e-commerce based on the regional advantages of the region. However, cross-border e-commerce involves trade between two countries. Different economic development, market environment, regulatory policies and customs will have a direct impact on cross-border ecommerce development.

In this regard, there is a lack of research on crossborder electronic commerce with the BRICS countries, so the strategic analysis of the Cross-border E-commerce in Henan Province will help to understand the current situation and formulate development plans on this basis.

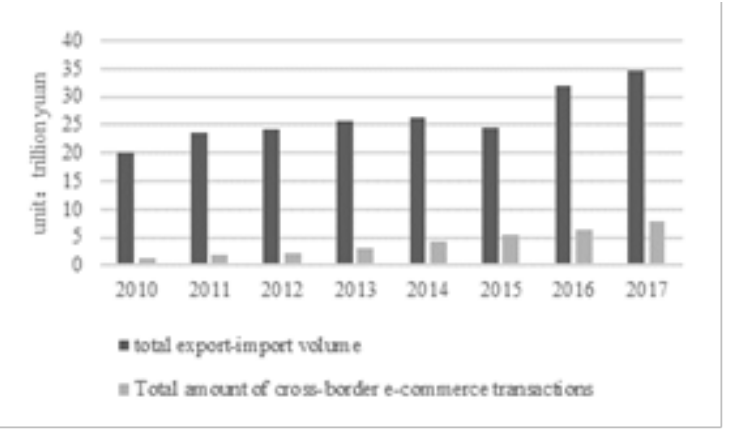

Fig. 1 Data on cross-border e-commerce trade

\section{THE MEANING OF CROSS-BORDER E- COMMERCE AND THE NECESSITY OF DEVELOPING CROSS-BORDER ELECTRONIC COMMERCE WITH BRICS COUNTRIES}

\subsection{The meaning of cross-border e-commerce}

Cross border e-commerce refers to the transactions and online payment of consumers in different countries relying on e-commerce platform (Jin Liang,2016), and through cross-border logistics to achieve commodity trading and distribution.

According to the differences between the two sides of the transaction, the current cross-border e-commerce has three main forms:

First, the traditional manufacturing, trading enterprises or brokers release the product information through the large-scale cross-border e-commerce service platform, global customers or intermediaries carry out the international trade with the information publisher through this platform.

Second, merchants use the online store to sell goods to another country's enterprises or end-users through the third-party cross-border e-commerce platform.

Third, the enterprises engaged in cross-border trade to use the existing information advantages and channel advantages to establish an independent Cross-border website, and directly sale to the global end-users. 
2.2 The necessity of developing cross-border electronic commerce with BRICS countries

\subsubsection{Population growth in the BRICS bring the} growth of potential consumers

In the BRICS countries, Brazil, India have an advantage of population, which bring the growth of potential consumers. Meanwhile, in recent years, the rapid development of the mobile Internet and related ecommerce potential there, young people in the new era will have higher sense of identity for cross-border ecommerce (Xiao Jiang, 2017). The continuous development of economy and disposable income also makes their ability to take on all the benefits of crossborder e-commerce (Xiaoping Cao,2016).

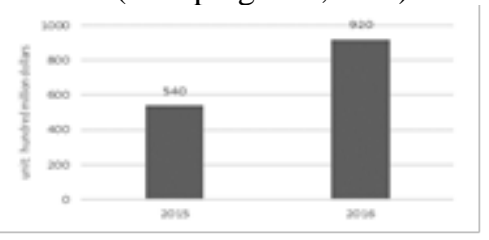

Fig. 2 Data on cross-border e-commerce transactions in the BRICS countries

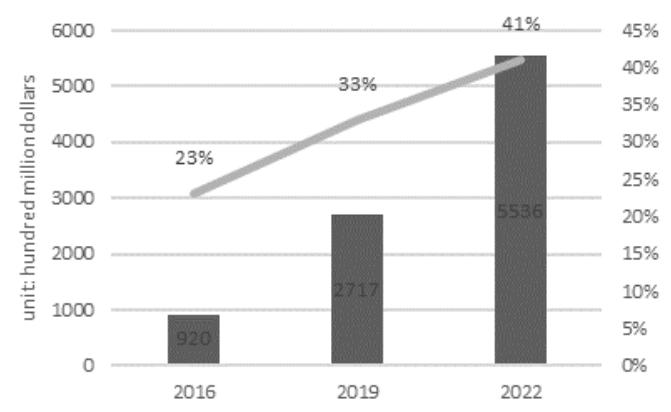

Fig. 1 The scale of cross-border E-commerce in the next few years and the rate in the global market

2.2.2 The development of cross-border e-commerce supported by mobile Internet will help reduce the trade barriers

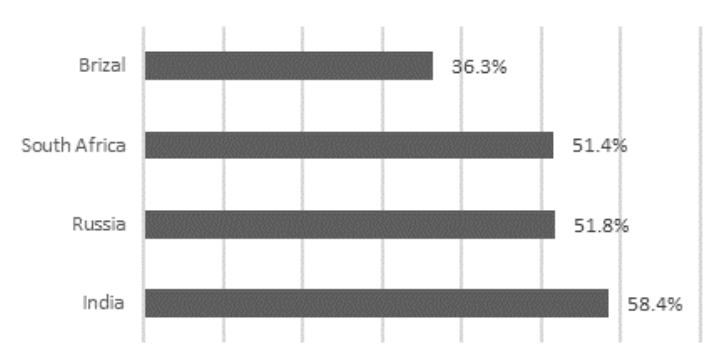

Fig. 2 Rate of wireless transactions of Aliexpress in BRICS

Advances in communications technology, the popularity of smart terminals, decline in rates, these factors make the mobile Internet becomes an important thrust to improve network coverage (Hu Yang,2016). Due to a late start in mobile development, the development potential of the BRICS countries is huge in the future, there will be more than $80 \%$ of Internet users through intelligent terminals for actions such as crossborder shopping, which will give further impetus to the popularity of mobile e-commerce (Yan Pang,2015). Meanwhile, cross-border e-commerce development has bypassed the traditional customs, quotas and other import and export system barriers, reduce trade links, improve the consumer experience, and will not be limited by geography, which can send them to anyone of the BRICS.

\section{THE CURRENT SITUATION OF CROSS BORDER E-COMMERCE IN HENAN}

\subsection{The products of cross-border e-commerce have regional characteristics}

The products of cross-border e-commerce have regional characteristics, and which is the advantage products of different regions, such as the machinery and equipment, shoes, wigs and so on. Due to the balance of light industry and heavy industry, the kinds of the goods are diverse in Henan Province.

\subsection{The scale of cross-border e-commerce is expanding}

Now, more and more companies are preparing to expand the international market using the cross-border ecommerce. And the traditional B2B industries is turning to B2C. Until 2017, the export scale of Henan Province is nearly 2 billion.

\subsection{The e-commerce industry agglomeration development}

Due to the advantage of industry, Henan Province has plan a lot of cross-border e-commerce parks. And it also formatting an industry chain using the way of attracting investing. Now many kinds of companies are agglomeration development, the industry chain and the ecosphere is also formatting. By complementary advantages, companies have get a progress.

\section{The STATUS OF CROSS-BORDER E- COMMERCE IN BRICS COUNTRIES}

\subsection{Introduction of BRICS}

The BRICS are an international organization of five countries, comprising China, Brazil, Russia, India and South Africa. The concept of "BRICS" was first proposed in a report published by Goldman Sachs in November 2003. Over the past decade, the BRICS have been increasingly influential, and more than 60 cooperative mechanisms has achieved between countries, and contributed more than 50\% percent of global economic growth.

\subsection{The status of cross-border e-commerce market in BRICS countries}

\subsubsection{Brazilian Cross-border E-commerce Market situation}

Brazil, the largest country in Latin America, has a population of 201 million, ranking fifth in the world. Its gross domestic product ranked first in South America, 
the second in the Western Hemisphere and the sixth in the world. In recent years, with its economic recovery, ecommerce in Brazil ushered in a new round of development. At 2016, Brazil has become the world's ninth largest retail market for electricity dealers, the good e-commerce foundation, the government's strong support also made the Cross-border electronic commerce obtains the rapid development.

At present, Brazil's cross-border e-commerce market presents the following characteristics: 1, At present, the top ranked e-commerce companies both have online platform and offline entity store.2, The number of crossborder online shopping is increasing rapidly due to the development of economic. 3, With the rapid development of e-commerce, mobile e-commerce has become a new trend of development.4, Since 2014, the Brazil e-commerce market is growing at a rate of $11 \%$, and the huge Internet users base provides a large space for the development of e-commerce.

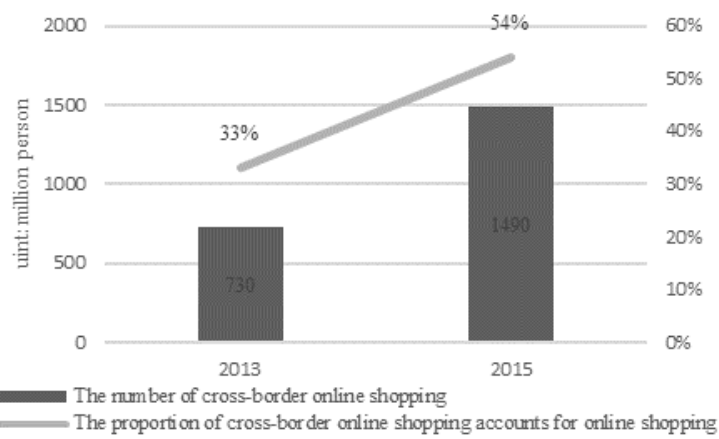

Fig. 3 The situation of cross-border e-commerce in Brazil

\subsubsection{The situation of cross border e-commerce market in Russia}

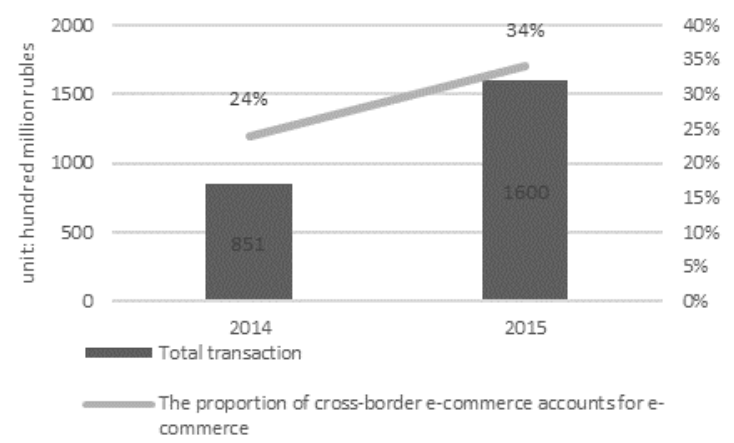

Fig. 4 The situation of cross-border e-commerce in Russia

Due to the industrial structure and other reasons, the development of e-commerce in Russia is relatively slow. Nevertheless, in recent years, thanks to the popularity of smart phones and the government's attention, the number of online shopping has also been greatly improved. In 2013, the number of online shopping reached 30 million, accounting for $23 \%$ of the total population, accounting for $50 \%$ of the total number of Internet users.

The cross-border e-commerce market in Russia has the following characteristics:1, the scale of cross-border e-commerce has been expanding. With the help of "The Belt and Road Initiative”, Chinese e-commerce platform has promoted the development of local e-commerce using its own advantages and experience. 2 Cross-border e-commerce market has great potential for development. The traditional Cross-border payment system and the backward logistics delivery channel are restricting the development of the Russian cross border electronic commerce. With the improvement of the conditions, Russia's e-commerce market will certainly prosper.

\subsubsection{Situation of Cross-border E-commerce market in India}

After several years of rapid development, the firsttier city's electricity market is nearing saturation, and Cross-border e-commerce will be the next development point. The large population and the strong desire of the younger generation provide the basis for the development of cross-border e-commerce. Under the background of "going out" of Chinese e-commerce platform, India is a good development object who has a same economic development situation with China.

India's Cross-border E-commerce market presents the following characteristics:1, Due to the inherent advantages of India's internet industry, India's crossborder e-commerce market has rapidly entered the era of mobile networks.2, India has some powerful ecommerce companies. After the screened of the market, a lot of e-commerce platforms have been bought by large companies, and these large platforms have become the most powerful rivals for cross-border e-commerce in the Indian market. 3, The impact of social media on crossborder e-commerce has increased dramatically. The consumption guidance and advertising role of social media is gradually promoting the development of Crossborder network shopping.

\subsubsection{The situation of Cross-border E-commerce markets in South Africa}

Unlike other BRICS countries, both domestic and Cross-border E-commerce are in the early stages of development in South Africa, With the entry and investment of many foreign electric power platforms, the number of its electric quotient is in the growing stage, and as the most developed country in Africa, the development space of cross-border e-commerce in South Africa is still very large.

At present, the Cross-border E-commerce market in South Africa presents the following characteristics: 1, The development of Cross-border e-business infrastructure is uneven. The younger generation is keen on online shopping, and the entry of large electrical platforms of the United States, China and the UK provides a basis for cross-border shopping for the younger generation in South Africa. The mature and reliable payment system has further facilitated the buying experience for young people. 


\section{RESEARCH ON THE DEVELOPMENT OF CROSS-BORDER E-COMMERCE BETWEEN HENAN PROVINCE AND BRICS COUNTRIES}

\subsection{Developing advantages}

\subsubsection{Regulatory model and management system are initially in line with international standards}

According to the China (Henan) free trade test area overall program, in the development of cross-border ecommerce in the FTA, we need to use the former national treatment and negative list management system, and strive to build a suitable after the supervision system, Foreign investment enterprises need not to be approval when invest the field outside the negative list, and this simplifies the process of cross-border e-commerce transactions in the trial area. These policies not only improve the efficiency of government administration, but also reduce the development costs of enterprises

\subsubsection{Henan Province has a favourable geographical position}

Henan has unique advantages in transportation. First of all, Henan province actively participate in the "The Belt and Road" construction, Henan has initially constructed a "dual hub" strategy with Henan Province as the hub of Asia Pacific and Luxembourg Henan Province as the hub of Europe and America. Secondly, Henan's domestic transportation network is relatively developed. Third, thanks to Lu cargo driven by the rapid development of the aviation logistics in Henan Province, a number of companies have offices in Hong Kong aviation physical and Zhengzhou has also become a major national logistics center. When developing crossborder e-commerce in BRICS countries, a convenient and efficient cross-border logistics system is a guarantee for the success.

\subsubsection{Henan's superior products are needed by the BRICS}

As the five most important developing countries in the world, the cross-border e-commerce of the BRICS has many complementary aspects in terms of product demand, price acceptance capacity and so on. As an important manufacturing province in China, Henan has advantages in the global market for its price, quality and variety, the cost is also at the lowest level in the world, and it has unique advantages in carrying out cross-border e-commerce. In recent years, Henan's electronic information, equipment manufacturing, automotive and parts and other emerging manufacturing scale is gradually increased. As of 2017, the income of the electronic information industry was 365 billion 610 million yuan, and the output of smart phones was more than 200 million, accounting for $1 / 7$ of the total output of the world.

\subsection{Development disadvantages}

\subsubsection{Trade rules need to be reconstructed}

As China's development of foreign trade started late, the discourse power in international trade negotiations is weak, the resulting adverse impact on cross-border ecommerce is particularly evident ${ }^{[11]}$. In 2016, China's international trade transactions accounted for $14 \%$ of the global total, but we have to follow the trade rules developed by western developed country, which greatly restricts the development of cross-border e-commerce and national interests. Meanwhile, the traditional international trade clearance procedures are cumbersome, and mode of operation of intermediaries can't meet cross-border e-commerce's evolving new forms and new demands. For example, Russia, as one of the BRICS, the rapid growth of e-commerce retail market, there are many e-commerce platforms from the United States, Europe and China, but the government does not have a complete policy, the products of cross-border ecommerce are sent to consumers after dozens of procedures, its operational environment is more complicated, which is a disadvantage for cross-border ecommerce enterprise.

\subsubsection{The extension of cross-border e-commerce logistics networks need to be strengthened}

Benefits from national policy support and Government attention, Henan Province has made significant progress in cross-border e-commerce logistics construction in recent years, and it also related to major air ports with BRICS countries, which greatly improving the efficiency of the Henan Province route logistics. But due to a late start in cross-border e-commerce development in our province, we lack the logistics enterprise communication and contact with the other BRICS countries, which delay the time of arrival of good to the consumers. "The last mile" problem exists not only in our country, but are weak in Russia, Brazil and India. For example, in Russia, a vast territory makes ecommerce orders of high distribution cost, goods turnover need a long time. In India, infrastructure is extremely poor, and services all over the country's logistics enterprises, quality and reliability of road and rail networks are restricting the development of crossborder e-commerce.

\subsubsection{Henan Province information construction of cross-border e-commerce is not perfect}

In order to sustain their development, we must widely rely on informatization construction Set so that constant transformation and upgrading of traditional industries. Despite the Henan Province in this crossborder e-commerce has made considerable progress, but, at the time of development of business with BRICS, its lack of information continue is several. First of all, with BRICS countries, cross-border e-commerce products are used postal packet mode, which made the information cannot follow. In time. Secondly, cross-border ecommerce logistics involved in domestic and foreign markets, there is exchange of information asymmetry between them. Thirdly, the payment is a challenge for cross-border e-commerce, particularly in India, whose logistics tracking system, online payments and network information construction face with a great challenge. 


\subsubsection{Cross-border e-commerce is faced with the pressure of transformation and upgrading}

Import and export trade in Henan province are mainly concentrated in agriculture, wholesale and retail trade and manufacturing, which has a low added value ${ }^{[12]}$. Beside smartphone, Henan province exported commodities at the lower end of the chain, mainly concentrated in the resource-based, low technology content and low added value of the product. There is a large gap with the developed area in the export industrial structure, the technological content of products, innovative aspects compared and Exports of large complete sets of equipment and high technology products is far below the national average. Now, the short boards of innovation is not obvious when carry out the cross-board e-commerce with the BRICS.

However, as the promotion of economic development in the BRICS countries and consumption level of the people, the problem will become more severe, Low innovation capability, no major industry chain, which will restrict future Henan Provinces in the further development of cross-border e-commerce.

\section{RESEARCH ON COUNTERMEASURES OF DEVELOPING CROSS-BORDER ELECTRONIC COMMERCE BETWEEN HENAN PROVINCE AND BRICS COUNTRIES}

\subsection{Promote the development of scientific research and technology innovation}

The saturation of traditional manufacturing industry market, weakening of investment, capital return and trade protectionism, these negative factors have prompted the industry to upgrade. Benefit from a new round of technological revolution, smart terminal manufacturing has become the core of new industries. However, only one is not enough to support the overall development of the industry. Cross-border e-commerce needs further improving. cooperation with scientific research institutions and improve the technical conversion. Traditional industries such as manufacturing need to be led its online operations.

\subsection{Integration of cross-border e-commerce services resources, innovate the e-commerce mode}

International brand reflects the product's market value and influence (Hu Chen and Xingwei Xie,2015), Henan Provinces lack such big international brands. Meanwhile, the lack of financial support and experience in cross-border trade, which make small enterprises facing difficulties in international cooperation, such as high transaction costs. Therefore, through the development of large data to expand overseas brands, integrate similar advantages in the profit areas, improve the influence and competitiveness of the products within the BRICS countries, and create a lot of first-class enterprises. Using the power of these enterprises to drive development of the small enterprises in Henan, which can form an industry alliance (Jinlong Li,2015). By doing so, we can form a virtuous cycle, achieve the purpose of collaborative innovation.
6.3 Innovate the relationship between the cross-board e-commerce, enhance the level of technology innovation.

Development of e-commerce has led to the development of the logistics industry. The requirement of cross-board e-commerce is more comprehensive for logistics enterprises, which bring a big challenge for these companies. When developing cross-border ecommerce with the BRICS countries. More types of goods also contributed to the growth of logistics services. That contribute to the formation of a new pattern of coordination and distribution, promoting cross-border ecommerce in bargaining power and achieve scale economic.

\subsection{Involved the trade making of cross-border e- commerce}

Different from Europe and other developed countries, in the area of cross-border e-commerce, there are many trade rules are not made, Henan Provinces should grasp this opportunity to attract more cross-border e-commerce giants, and make sure the local e-commerce enterprises can grow in good atmosphere. At the same time, we should use the "The Belt and Road" strategy as an opportunity to strengthen exchanges with countries along, and enhancing the influence in the e-commerce trade, lay down the material basis and guarantee for the formulation of new rules for cross-border e-commerce business in the new era, strengthen the power of right to speak when making the rules and regulations of crossboard e-commerce with BRICS countries

\section{CONCLUSIONS}

Judging from the perspective of policy, capital entry and market growth rate, at present, cross-border ecommerce of Henan Province are in the golden period of development, but it is different from the domestic ecommerce, the long supply chain, logistics and the payment have to adjust to the cross-border e-commerce. At the same time, the BRICS have the demand for ecommerce, it will provide a chance for Henan Province cross-border e-commerce. At with the help of policy, it will go through a period of rapid development

\section{REFERENCES}

[1] Huan, Chen, 2015. An Analysis of the Independent Brand Marketing Strategy Of The Cross-Border Electricity Suppliers, Jiangsu Commercial Forum. 2015(07), pp.32-34.

[2] Jinlong, Li, 2015. Exploring the Bonded Logistic Platform of Cross-border E-commerce in Yiwu, China Business and Market.2015 (07), pp.30-34.

[3] Xiao, Jiang, 2017. Research on collaborative innovation of cross-border e-commerce ecological chain in Zhengzhou Airport experimental area, Contemporary Economics 2017(13), pp.56-57.

[4] Xiao, Kun, 2015. Complementarities and Competitiveness Between China and the BRICS, REFORMATION \& STRATEGY. 2015(07), pp.184-190.

[5] Xuemei, Jie, 2013. Operation mechanism of synergic innovative effect: a perspective from metropolitan region, 
Studies in Science of Science. 2013(12), pp.1907-1920.

[6] Xuemei, Zhang, 2016. Research on collaborative innovation of Ningbo cross-border electrical business logistics, Modern Marketing.2013 (12), pp.158-160.

[7] Xiaoping, Cao, 2016. Research on the development mode of Jinhua cross-border electric quotient in the perspective of collaborative innovation, Market Modernization. 2016(05), pp.38-39.

[8] Xiaorui, Zhou, 2016. Research on problems and countermeasures of cross-border electrical business logistics in Zhengzhou Airport, China Management Informationization.
2016(16), pp.147-148.

[9] Yan, Pang, 2015. Research on International Logistics Operation Mode under the Environment of Cross-border Ebusiness, China Business and Market. 2015(10), pp.15-20.

[10] Yang, Hu, 2016. Research on the strategy of e-commerce and logistics development in large data age, Commerce. 2016(02), pp.9-10.

[11] Yuanyuan, Zhou. The influence of cross-border electricity merchants on the transformation and escalation of foreign trade in Henan province. Modern Economic Information. 2017(02), pp.477-478. 